\title{
DETERMINE THE PROBABILITY OF PASSENGER SURVIVAL IN AN AVIATION INCIDENT WITH FIRE ON THE GROUND
}

Turko V.P., Vinogradov L.A., Ivakhnenko A.A.

Conducting the risk level of aviation incident with fire and the impacts of contingence affecting factors on people. Base on statistical data of aviation incident, the model of aircraft fire situation on the ground was offer.

Keywords: aircraft; aviation incident; statistical model; probability of getting in an aviation incident; probability of survival in an aviation incident.

\section{Introduction}

Emergence of every aviation incident usually a consequence not because of individual reason, but because of chain result of the relevant prerequisites. The initiator causal chain in the aviation incident usually because of people mistake with deficiently professional preparedness, refusal of technics and equipment or unauthorized external effects. The predominant role of human factor in the formation of the primary prerequisites according to different sources hesitate from $60-70 \%$ in industry, others civilian facilities and $80-90 \%$ in aviation $[1,7]$.

ICAO initiated on determining risk that aimed at improving level of fly safety, which based on operation information of fly safety $[4,8]$. During the period 2006 to 2010 aviation incident related with safety operation on runway, make up $59 \%$ of the total number of incidents, 
$29 \%$ of all incidents fatalities and $19 \%$ of it dead. While incidents cause by loss control in flights is only $4 \%$. Fly safety also related with the survival of people during aviation incident that can end without death as well as the presence or absence of fire on the ground.

\section{The main reasons and fire situations in aviation incidents of aircrafts}

Regardless of the type of aircraft (VS), the main reasons are poor control over the aircraft at low altitude, landing, taxiing, and fire/smoke after hitting the ground. The main factors leading to the death and injury of people in AI are increased shock overload - 80\% fatalities and 75\% injuries, poisoning from smoke and toxic gases $-16 \%$ fatalities and $14 \%$ injuries, and other factors $-3 \%$ fatalities and $10 \%$ injuries.

Obviously, the passenger can survive only if the AI is on the ground (or water). At the same time, eliminating the death toll from aircraft depressurization, shock, or pain because of ill health, the survivors still have to face with the problem of survival in case of fire of aircraft in the open vicinities of aviation incident.

Depending on the combination of these factors in [2] a typical amount ten cases of emergency state is presented. Presented cases are based on the generalization of AI materials that took place in the territory and or in the terminal area, i.e., in the area of accident rescue teams (ART) of airport.

In Table 1, these cases are arranged in order of complexity of firefighting and rescue conditions (evacuation) distressed passengers.

A list of events in case of fire emergencies on the ground [2] (Table 1).

As you can see, the main factors hampering rescue or self-rescue is the condition of the fuselage, the volume of the fire (its intensity, ignition area), and the passengers the ability to perform self-rescue. It should be noted that these factors must be added to the remoteness of the place of accident and rescue services from the airport (ACC) [2]. 
Table 1.

\begin{tabular}{|c|c|c|c|}
\hline \multirow[b]{2}{*}{$\begin{array}{l}\text { № } \\
\mathrm{AI}\end{array}$} & \multicolumn{3}{|c|}{ Factors characterizing AI } \\
\hline & $\begin{array}{c}\text { The position and condition of } \\
\text { the fuselage }\end{array}$ & The nature of fire on aircraft & $\begin{array}{c}\text { Status of } \\
\text { passengers }\end{array}$ \\
\hline 1 & \multirow{4}{*}{$\begin{array}{l}\text { Located on the landing gear } \\
\text { completely, no damage }\end{array}$} & Fire engine & \multirow{4}{*}{$\begin{array}{l}\text { All or most of } \\
\text { the passengers } \\
\text { are capable of } \\
\text { independent } \\
\text { movement and } \\
\text { evacuation }\end{array}$} \\
\hline 2 & & Burning parts falling & \\
\hline 3 & & $\begin{array}{l}\text { low-intensity fire outside of } \\
\text { the fuselage }\end{array}$ & \\
\hline 4 & & $\begin{array}{l}\text { Fire under the fuselage of jet } \\
\text { fuel spilled }\end{array}$ & \\
\hline 5 & $\begin{array}{l}\text { Fuselage (passenger cabin) } \\
\text { partially damaged }\end{array}$ & $\begin{array}{l}\text { Fire spilled jet fuel around } \\
\text { the fuselage of medium } \\
\text { intensity }\end{array}$ & $\begin{array}{l}\text { Some of the } \\
\text { passengers } \\
\text { are not able to } \\
\text { self-rescue }\end{array}$ \\
\hline 6 & & $\begin{array}{l}\text { Fire spilled fuel under the } \\
\text { fuselage of medium intensity }\end{array}$ & \\
\hline 7 & & & \\
\hline 8 & $\begin{array}{l}\text { The fuselage is significantly } \\
\text { damaged }\end{array}$ & \multirow{3}{*}{$\begin{array}{l}\text { Fire spilled under the fuse- } \\
\text { lage of jet fuel, the fire inside } \\
\text { the fuselage }\end{array}$} & \multirow{3}{*}{$\begin{array}{l}\text { Most of the } \\
\text { passengers are } \\
\text { not capable of } \\
\text { independent } \\
\text { movement and } \\
\text { evacuation }\end{array}$} \\
\hline 9 & $\begin{array}{l}\text { The fuselage is on the ground, } \\
\text { the passenger cabin is signifi- } \\
\text { cant damage }\end{array}$ & & \\
\hline 10 & $\begin{array}{l}\text { The fuselage flipped, does } \\
\text { considerable damage }\end{array}$ & & \\
\hline
\end{tabular}

Ensuring the survival conditions of the people and reducing the severity of the consequences of the AI with the fire on the ground can be achieved if follow this requirements [3].

- Extinguishing the fire on the aircraft should begin prior to exceeding the maximum permissible value of fire hazards;

- Localization fire time and fire extinguishing primary combustion area must not exceed the set value;

- Localized fire containment time should be sufficient for the evacuation of the emergency aircraft.

In addition, you must be guided by the principle and building forces and means involved in firefighting in the aircraft.

Mathematical modeling makes it possible to measure that and it is important to compare the relative frequency of occurrence of the 
danger and the fire situation, the probability of passengers death in a given situation, and to identify the most immediate dangers in terms of fire safety types of aircrafts and airlines.

Impacts of fire hazards at the AI can be determined based on the results of available statistical data relating to similar incidents. To determine the probability of survival in a fire because of the AI offers a simple probabilistic model of survival for passengers caught in AI. To determine the parameters of such a model it is necessary to analyze and process the statistical data on the AI with a fire on the ground. The most common indicators used to assess the static level of flight safety are the number of AI and the number of casualties in them. Therefore, to identify the main factors of AI, it is necessary that we use the statistical data on incidents registered during a sufficiently long time. Obviously, for a correct assessment of the model, parameters should strive to handle a more uniform data on the class and type of aircraft, be excluded from the statistical data sampling, instances of terrorist attacks, military operations, fire in the air, aircraft mid-air collision and etc. [1].

\section{Probabilistic model situations of fire in aircraft in aviation incidents}

The probability of survival for the passengers in case of fire in aircraft on the ground depends on:

- The number of passengers and evacuation (depending on the type of aircraft and flight qualification of the personnel);

- Proximity of the airport to the place of the AI;

- The value of the ground breaking the fuselage and especially the passenger cabin;

- The ability of passengers to self-rescue;

- The nature and intensity of the fire (fuel spill, fire, power plant, the fire inside the passenger cabin, etc.).

These parameters determining the survival of the passengers in case of fire in aircraft on the ground should be assessed in the analysis 
of statistical data and the organization of their collection. It is obvious that the proposed model will consist of a matrix of an emergency event and the probability of survival of the passengers.

Then the matrix event of emergencies (Table 2) will be as follows:

Table 2.

Emergency events Matrix

\begin{tabular}{|l|c|c|c|c|c|c|c|c|c|c|}
\hline \multicolumn{1}{|c|}{ State of emergency (i) } & 1 & 2 & $\ldots$ & $\ldots$ & $\mathrm{i}$ & $\mathrm{i}+1$ & $\ldots$ & $\ldots$ & $\mathrm{n}-1$ & $\mathrm{n}$ \\
\hline $\begin{array}{l}\mathrm{P}_{\mathrm{i}}-\text { the likelihood of passenger } \\
\text { survival in the i-th situation }\end{array}$ & $\mathrm{P}_{1}$ & $\mathrm{P}_{2}$ & $\ldots$ & $\ldots$ & $\mathrm{P}_{\mathrm{i}}$ & $\mathrm{P}_{\mathrm{i}+1}$ & $\ldots$ & $\ldots$ & $\mathrm{P}_{\mathrm{n}-1}$ & $\mathrm{P}_{\mathrm{n}}$ \\
\hline $\mathrm{N}_{\mathrm{i}}$ - probability of i-th situation & $\mathrm{N}_{1}$ & $\mathrm{~N}_{2}$ & $\ldots$ & $\ldots$ & $\mathrm{N}_{\mathrm{i}}$ & $\mathrm{N}_{\mathrm{i}+1}$ &.. & $\ldots$ & $\mathrm{N}_{\mathrm{n}-1}$ & $\mathrm{~N}_{\mathrm{n}}$ \\
\hline
\end{tabular}

The number of states $\mathrm{n}$, generally can be taken from Table 1, where $\mathrm{n}=10$. Suppose that the event matrix (Table 2) is focused on the most favorable situations $(i=1)$. AI made almost within the precincts of the airport runway, the destruction of the passenger cabin is virtually absent, almost all the passengers are able to self-rescue, fuel spilled is minimal to catastrophic $(i=n)$. AI occurred in a remote area of the airport, substantial damage to the passenger cabin, the majority of passengers struggled to self-rescue, extensive spilled fuel.

Obviously, the probability of survival of passengers $\mathrm{Pi}$ in favorable situation is the greatest, and catastrophic - the smallest, ie:

$$
\mathrm{P} 1>\mathrm{P} 2>\ldots \mathrm{Pi}->\mathrm{Pi} \ldots . .>\mathrm{Pn}
$$

where $\sum_{i=1}^{n} P_{I}=1.0(1)$ is the probability of falling into a particular situation $\mathrm{N}_{\mathrm{i}}$. Logically it can be assumed that the most common situation is close to catastrophic and beneficial. The intermediate situation is likely to occur much less frequently:

$$
\mathrm{N}_{(1.2 .3 \ldots)}>\mathrm{N}_{\mathrm{i}} \ldots<. . \mathrm{N}_{(\mathrm{n}-1, \mathrm{n})}
$$

Just as in (1) $\sum_{i=1}^{n} N_{I}=1.0$ (2)

In this setting of full matrix emergency events will have a minimum of $16-24$ cases; 4 situation, with two extreme values: 
- Close to airport - far from the airport;

- Fuselage lightly broken - badly damaged fuselage;

- Little spilled fuel - fuel spilled and ignited extensively;

- Passengers can evacuate on their own - passengers require help evacuating.

Such statistics are not present in the media - although in principle the organization collecting such statistics would be of some benefit, and given the opportunity to apply the methods of multivariate statistical analysis.

Therefore, assuming that the ability of passengers to self-rescue and degree of fuel spill directly correlated with the degree of destruction of the fuselage, simplify the array of events to nine states:

- AI degree of proximity to the airport, "airport" - "near the airport" - "at a distance from the airport."

- The degree of destruction of the fuselage with the AI: "low" "medium" - "significant"

Matrix events (Table 2) will become as follows (Table 3).

Table 3 .

Grouped alarm events Event matrix

\begin{tabular}{|l|c|c|c|}
\hline \multirow{2}{*}{ Degree of destruction } & \multicolumn{3}{|c|}{ Distance from the airport } \\
\cline { 2 - 4 } & $\begin{array}{c}\text { In an Aeroport, } \\
\mathrm{i}=1\end{array}$ & $\begin{array}{c}\text { Near the } \\
\text { airporti }=2\end{array}$ & $\begin{array}{c}\text { Far from the } \\
\text { airporti }=3\end{array}$ \\
\hline Small, $\mathrm{j}=1$ & $\mathbf{P}_{11}$ & $\mathbf{P}_{12}$ & $\mathbf{P}_{13}$ \\
\hline Central, $\mathrm{j}=2$ & $\mathbf{P}_{21}$ & $\mathbf{P}_{22}$ & $\mathbf{P}_{23}$ \\
\hline Much, $\mathrm{j}=3$ & $\mathbf{P}_{31}$ & $\mathbf{P}_{32}$ & $\mathbf{P}_{33}$ \\
\hline
\end{tabular}

We continue further simplification of the model associated with the necessity of treating the available statistical data. Let us assume that the state of emergency situations are divided into I - «favorable»with a high degree of probability of survival, and II - «adverse» - with 
a moderate degree of probability of survival. III - «catastrophic»unlikely to survive in these situations. These groups are respectively highlighted in green, yellow, and red in Table 3. The probability falling into a dangerous situation of danger I, II or III (Table 3) denote respectively $\mathrm{N}_{\mathrm{I}}, \mathrm{N}_{\mathrm{II}}$ and $\mathrm{N}_{\mathrm{III}}$. In this case, the source table alarms statuses event matrix (Table 3) takes the following form:

Table 4.

Matrix grouped emergencies

\begin{tabular}{|l|c|c|c|}
\hline \multicolumn{1}{|c|}{ State of emergencies $(\cdot)$} & $\mathrm{I}$ & II & III \\
\hline The probability of $\mathrm{N}(\cdot)$ of an emergency $(\bullet)$ & $\mathrm{N}_{\mathrm{I}}$ & $\mathrm{N}_{\mathrm{II}}$ & $\mathrm{N}_{\mathrm{III}}$ \\
\hline $\begin{array}{l}\text { passenger survival probability } \mathrm{P}(\cdot) \text { if it enters } \\
\text { the emergency }(\bullet)\end{array}$ & $\mathrm{P}_{\mathrm{I}}$ & $\mathrm{P}_{\mathrm{II}}$ & $\mathrm{P}_{\mathrm{III}}$ \\
\hline
\end{tabular}

Thus, the total probability of survival of passengers in contact with the ground in a situation with a fire on the ground can be calculated using the formula:

$$
P_{\text {alive }}=\sum_{I=1}^{I=3} P_{I} N_{I}
$$

or the average estimate of the probability to survive a passenger, got into the AI with fire.

Of course, to formulate a probabilistic conditions of an emergency $\mathrm{N}(\bullet)$ is very difficult and not so important in principle. But, the probability of survival, $\mathrm{P}(\bullet)$ can be calculated by an adaptation for flight accidents methods of calculation of survival in fires in civil and industrial buildings [5].

\section{Analysis of statistical data to assess the probability of survival of passengers in an emergency with fire}

Let us try to evaluate the given parameters of the proposed model (3) according to the available statistical data [4,8]. Consider the data conditionally accepting state groups, depending on the distance (group I to III) AI from the airport. 
Table 5.

Statistical data on the AI to fire depending on the distance from the airport

\begin{tabular}{|l|c|c|c|c|}
\hline \multicolumn{1}{|c|}{ Group states j } & I & II & III & Total \\
\hline $\mathrm{N}_{\text {fire }}$ & 69 & 31 & 47 & 147 \\
\hline$N_{\text {deaths }}$ & 301 & 614 & 937 & 1852 \\
\hline$N_{\text {alive }}$ & 4041 & 456 & 688 & 5185 \\
\hline$N_{\text {passangers }}$ & 4342 & 1070 & 1625 & 7037 \\
\hline
\end{tabular}

where

$N_{\text {fire }}$ - number of fires;

$N_{\text {deaths }}$ - who died in a fire on the ground

$N_{\text {alive }}$ - surviving a fire on the aircraft

$N_{\text {passengers }}$ - the total number of passengers who find themselves in a situation with a fire on the aircraft.

We estimate the probability of occupant survival $P j$, who turned in AI group $-j$

group I $P=\frac{N^{\text {alive. }}}{\text { Npass }}=\frac{4041}{4342}=0.93$

group IIP $=\frac{N^{\text {alive. }}}{\text { Npass }}=\frac{456}{1070}=0.42$

group IIIP $=\frac{N^{\text {alive. }}}{\text { Npass }}=\frac{688}{1625}=0.42$

Rate $N_{j}$ hit passengers trapped in the AI group $-j$

Group I: $N=\frac{N^{\text {fire }}}{\sum n^{\text {fire }}}=\frac{69}{147}=0.47$

Group II $: N=\frac{N^{\text {fire }}}{\sum n^{\text {fire }}}=\frac{31}{147}=0.21$

Group III: $N=\frac{N^{\text {fire }}}{\sum n^{\text {fire }}}=\frac{47}{147}=0.32$

The data show that all AI with fire is likely to occur at the airport (or near) - Group I situations, or away from it (Group III situations), 
see (2). In addition, the possibility of passenger survival is greatest in the case of situations of group I, the compositions according to the model (3) matrix states and survival, we get:

Table 6.

The initial matrix event of emergencies

\begin{tabular}{|l|c|c|c|}
\hline $\begin{array}{l}\text { Group states } \\
-j\end{array}$ & I & II & III \\
\hline$P_{\text {ialive }}$ & 0.93 & 0.42 & 0.42 \\
\hline$N_{\text {isituation }}$ & 0.47 & 0.21 & 0.32 \\
\hline
\end{tabular}

Based on the data, the average (full) probability of survival of passengers (3) is equal to

$$
P_{\text {alive }}=\sum_{I=1}^{I=3} P_{I} N_{I}=0.660
$$

Despite that when the data was taken into account only the distance AI from the airport received a full passenger survival probability based on the probability that in a particular situation is equal to 0.660 , while the calculation of the probability of survival without regard to conditions hit probability in an emergency situation (arithmetic mean) we have:

$$
\mathrm{P}_{\text {survivors. }=\mathrm{N} \text { is alive. } / \mathrm{N} \text { passengers }}=5185 / 7037=0.737 \sim 0.74
$$

which is almost $15 \%$ overstates the estimate of survival.

\section{Determine the probability of passenger survival rate in an emergency per year}

Determine the probability can be obtained based on one of three approaches:

1) Direct determine based on statistical data processing;

2) Analysis the model that relates to the likelihood of the considering event with probabilities of other events;

3) In the analysis, based on expert judgment 
Let's conduct an analysis of statistical data on the ratio of the amount of aircraft emergencies per year for the group companies in the US [4.8].

Table 7.

Initial data for the AI with a fire in the period of 1995-2004

\begin{tabular}{|l|c|}
\hline \multicolumn{1}{|c|}{ Index } & AI with fire \\
\hline Number of accidents & 112 \\
\hline Number of passengers involved in fire & 7017 \\
\hline Amount of deaths & 1917 \\
\hline
\end{tabular}

It is evident that the number of passengers caught in a fire in AI equaling 7017, during the same period as passengers that died in 1917, averaging 112 .

Simple range probability of survival according to the formula:

$$
P_{\text {alive }}=\frac{N^{\text {pass }}}{N^{\text {fire }}}=\frac{7017-1917}{7017}=0.73
$$

Presented probability of survival for a group of companies under consideration almost equal to the arithmetic mean of the probability of survival for all US airlines [4.8]. Statistics examined airlines presents data on the hit rate of aircraft in different emergencies (see. Table 1), which is shown in Table 8.

Table 8 .

Table initiating event of emergencies

\begin{tabular}{|c|c|}
\hline The reason for the AP ( situation i) see Table 1 & Number of AP in a situation i Ni \\
\hline $\mathrm{i}=1$ & 15 \\
\hline $\mathrm{i}=2$ & 14 \\
\hline $\mathrm{i}=8$ & 12 \\
\hline $\mathrm{i}=10$ & 10 \\
\hline
\end{tabular}

Then estimate the probability of contact with AI event group $j$, (I = $1,2,3)$ for the consideration of the airlines. 
Table 9.

Table probability event of emergencies

\begin{tabular}{|c|c|c|c|c|c|c|}
\hline Group states - $\mathrm{j}$ (Table 1$)$ & \multicolumn{2}{|c|}{ I group } & II group & \multicolumn{2}{|c|}{ III group } & Total \\
\hline Status - i & 1 & 2 & - & 8 & 10 & - \\
\hline number of accidents & 15 & 14 & \multirow{2}{*}{ - } & 12 & 10 & \multirow{2}{*}{51} \\
\hline Probability situatsii - $\mathrm{i}$ & 0,294 & 0,275 & & 0,235 & 0,196 & \\
\hline $\begin{array}{l}\mathrm{Ni} \text { - the probability of } \mathrm{j} \text {-th } \\
\text { group of states }\end{array}$ & \multicolumn{2}{|c|}{0,57} & - & \multicolumn{2}{|c|}{0,43} & - \\
\hline
\end{tabular}

Knowing the probability of occurrence of situations and the likelihood of falling into a dangerous situation from the model (3), we can determine the probability of passenger survival for the companies under consideration:

$$
P_{\text {survivors }}=0.66
$$

To estimate the probability of a passenger entering the AI with fire and their survival in it for the companies under consideration, we will determine the number of passengers transported per trip.

Total passengers trapped in the AI with fire: $\mathrm{N}_{\text {pass }}=7017$;

Number of fires: $\mathrm{N}_{\text {fire }}=112$.

It is obvious that the average number of passengers per flight who have fallen in the AI with fire.

$N_{\text {pass. }}=\frac{N_{\text {pass }}}{N_{\text {fire }}}=\frac{7017}{112}=63$ (aircraft type, close to the medium)

Table 10.

The total number of flights of one airline per year [4.8]

\begin{tabular}{|c|c|c|}
\hline $\begin{array}{c}\text { Amount of one type } \\
\text { aircraft, } \mathrm{K}\end{array}$ & $\begin{array}{c}\text { Average flight of one } \\
\text { aircraft per year, } \mathrm{N}_{\mathrm{i}}\end{array}$ & $\begin{array}{c}\text { Total number of flights } \\
\text { per year, } \mathrm{N}=\mathrm{K} * \mathrm{~N}_{\mathrm{i}}\end{array}$ \\
\hline 39 & 1300 & 50700 \\
\hline
\end{tabular}

Then all airline passengers transported under consideration per year $N_{\text {pass }}=50700 * 63=3.2$ mil.pas./year

The number of passengers who find themselves in a situation with a fire (in a year): 


$$
N_{\text {Pass }}^{\text {fire }}=\frac{\mathbf{7 0 1 7}}{\mathbf{1 0}}=\mathbf{7 0 2} \text { Pass. } / \text { Year }
$$

The probability of the passenger airlines get considered in the AI to fire (in a year)

$$
P_{\text {Per year }}^{\text {fire. }}=\frac{N^{\text {pass }} \text { fire }}{N^{\text {allpass }}}=\frac{702}{3.2 * 10^{6}}=2.2 * 10^{-4}
$$

The probability of the passenger to be in AI with fire and die in it, for the given airlines a year, is equal to:

$P_{\text {death }}=P_{\text {fall into the fire. }} *\left(1-P_{\text {to survive in a fire })}\right)$

$$
P_{\text {death }}=2.2 * 10^{-4} * 0,34=0,748 * 10^{-4}
$$

Regularly likely to be in the fire and death for people in case of fire of building constructions is $10^{-6}[6]$.

It can be seen that the passenger aircraft during the aviation accident with the fire on the ground (in a year), is 75 times more dangerous to the regulatory risk in the event of fire in the premises of building structures.

\section{Conclusion}

The proposed model makes it possible to assess the risk of the passengers killed in a fire situation on aircraft carriers and airlines and the compilation of the insurance fund for payments to the families of those killed and injured. In assessing, the level of risk of AI, we have to evaluate the exposure level of affecting factors on people in emergencies. With such a task may encounter expert, insurance companies and owners of companies. To assess the level of danger requires AI effects data, the number of casualties, economic damage. In fact, evaluation of the impact of factors affecting people and the aircraft comes down to the definition of two functions: the dependence of the number of fire hazards on the distance to the accident and the damage dependent on the number of factors.

The probability of survival at the AI with post-accident fire is lower than in a situation with a fire in civil engineering. Implementation of the developed model allows to quantitatively calculate the amount of fire hazards in the AI based on probabilistic method by direct process- 
ing of statistical data.

The resulting research evidence, increase the objectivity and probative conducted expert studies.

\section{References}

1. Khamidulina E.A. Simulation of dangerous processes in the technosphere. "Management of risks. System analysis and modeling.

2. Safonov S.K., Seleznev A.V. Methodical instructions. Methods of calculating the forces and means of fire protection in the planning of airport fire and rescue operations on aircraft. UVAU GA, Ulyanovsk 201253 c. ( Desktop Publishing, the Google)

3. Rogachev A.A. Efficiency fire fighting aircraft on the ground / A.A. Rogachev // Problems of safety. 1987. № 8. S. 78-88.

4. http://aviac.ru/statistics/697-statistika-aviacionnyh-proisshestviy-po-regionam.html

5. Method for determining the calculated values of fire risk in buildings, construction and structures of various classes of functional fire hazard: application to the Russian Emergency Situations Ministry order dated 30.06.2009. №382 (Access http://www.mchs.gov.ru).

6. Brushlinskii N.N. The role of fire statistics in the assessment of fire risks // N.N. Brushlinsky., Sokolov S.V. // The problem of security and emergencies. 2012.№1. S. 112-124.

7. Zubkov B.V., Sharov V.D. theory and practice of risk identification in aviation enterprises in the development of safety management systems. M.: MSTU CA, 2010. $196 \mathrm{~s}$.

8. Guidance on Safety Management Manual (SMM), Doc 9859-AN / 460. Second Edition - ICAO, 2009.

\section{DATA ABOUT THE AUTHORS}

Turko Vladislav Pavlovich, Executive Vice President of Scientific Research, Dr.Sc.Ing. with Expert Rights from Latvian Council of Science 
AVIATEST

1, Rezeknes Str., LV-1073, Riga, Latvia

vladislav.turko@mail.ru

Vinogradov Leonid Aleksandrovich, Academic, Master Sc.Eng.

Riga Technical University (Institute of Aeronautics)

1B-214, Lomonosov Str., LV-1019, Riga, Latvia

Ivakhnenko Andrey Andreevich, Assistant Professor, Management Chair, Candidate of Tech. Sci.

State Technical University - MADI

64, Leningradsky prospekt, Moscow, 125319, Russian Federation

ivakhnenko_aa@inbox.ru 